\title{
AVALIAÇÃO DOS EFEITOS DO ADENSAMENTO URBANO NA DINÂMICA HIDROLÓGICA DE BACIAS HIDROGRÁFICAS - APARECIDA DE GOIÂNIA - GO
}

\author{
EVALUATION OF THE EFFECTS OF URBAN \\ DENSIFICATION ON HYDROLOGICAL DYNAMICS OF \\ WATERSHED - APARECIDA DE GOIÂNIA - GO
}

EVALUATION DES EFFETS DE DENSITÉ URBAINE

SUR LA DYNAMIQUE HYDROLOGIQUE DES BASSINS

HYDROGRAPHIQUES - APARECIDA DE GOIÂNIA - GO

Elizon Dias Nunes - Universidade Federal de Goiás - Goiânia - Goiás - Brasil

elizonnunes@ufg.br

\author{
Lana Lima Borba - Pontifícia Universidade Católica de Goiás - Goiânia - Goiás - Brasil \\ lanalima.30@hotmail.com.br
}

\section{Resumo}

A expansão e 0 adensamento urbano nas últimas quatro décadas influenciaram na dinâmica hidrológica de bacias hidrográficas urbanas. 0 objetivo deste trabalho é avaliar a intensificação desse processo, tendo como base mudanças nos coeficientes de escoamento superficial em face de cenários de precipitação, e sua influência no aumento das estimativas de vazão de uma bacia hidrográfica em Aparecida de Goiânia. A metodologia consistiu na modelagem dos condicionantes por geoprocessamento, envolvendo precipitação, variáveis morfométricas, classes de cobertura e uso associadas aos tipos de solo, e seus efeitos nas estimativas de vazão em 1992, 2005 e 2016. Os resultados indicam uma estreita correlação espaço-temporal entre 0 adensamento urbano e as estimativas de vazão, sendo que, no exutório da bacia, a vazão máxima estimada passou de 16,2 em 1992 para cerca de 46,8 m³/s em 2016. No mesmo período e em toda a bacia, a redução do tempo de concentração foi de apenas 5,3 minutos, em contraste com 0 considerável aumento das estimativas de velocidade de escoamento das áreas densamente edificadas. Entende-se que os canais, juntamente com a planície de inundação, funcionaram como áreas redutoras da velocidade de escoamento, intensificadas pelo aumento e pela convergência de volumes de fluxo advindos das áreas mais elevadas.

Palavras-chave: Impermeabilização do solo, escoamento superficial, estimativas de vazão.

\section{Abstract}

The expansion and urban densification in the last four decades have influenced the hydrological dynamics of urban watershed. The goal of this paper is to evaluate the intensification of this process, considering the changes in the coefficients of runoff in the face of precipitation scenarios, and its influence in the increase of the flow estimates of a watershed in Aparecida de Goiânia. The methodology consisted in the modeling of geoprocessing conditioners, involving precipitation, morphometric variables, coverage and use classes associated with soil types, and their effects on flow estimates in 1992, 2005 and 2016. The results indicate a close spatial-temporal correlation between urban densification and flow estimates, and in the basin exudative the maximum estimated flow increased from 16.2 in 1992 to about $46.8 \mathrm{~m}^{3} / \mathrm{s}$ in 2016 . In the same period and in the whole basin the reduction of the concentration time was only 5.3 minutes in contrast to the considerable increase in the estimates of the flow velocity of the densely built areas. It is understood that the channels, 
herewith of the floodplain, functioned as reducing areas of the flow velocity enhanced by the increase and convergence of flow volumes from the higher areas.

Keywords: Soil sealing, runoff, estimates flows.

Résumé

L'expansion et la densité urbaine au cours des quatre dernières décennies ont influencé la dynamique hydrologique des zones fortement urbanisées. L'objectif de ce travail est d'évaluer l'intensification de ce processus, basée sur les changements dans les coefficients de ruissellement face aux scénarios de précipitations, et son influence sur l'augmentation des estimations de débit d'un bassin hydrographique à Aparecida de Goiânia. La méthodologie consistait à modéliser les conditionneurs de géotraitement, en incluant les précipitations, les variables morphométriques, les classes de couverture et d'utilisation associées aux types de sols et leurs effets sur les estimations de débit en 1992, 2005 et 2016. Les résultats indiquent une corrélation spatio-temporelle étroite entre les densités urbaines et les estimations de débit: dans le débit sortant du bassin, le débit maximal estimé est de 16,2 en 1992 à $46,8 \mathrm{~m}^{3} / \mathrm{s}$ en 2016. Dans la même période et dans tout le bassin, la réduction du temps de concentration n'était que de 5,3 minutes contrairement à l'augmentation considérable des estimations de la vitesse d'écoulement des zones densément construites. Il est entendu que les canaux, avec la plaine d'inondation, ont fonctionné comme des zones réductrices de la vitesse d'écoulement renforcé par l'augmentation et la convergence des volumes d'écoulement des zones supérieures.

Mots-clés: L'imperméabilisation du sol, ruissellement de surface, Les estimations de débit.

Introdução

Nas últimas quatro décadas, parte dos ambientes urbanos vem passando por acentuadas mudanças na cobertura e no uso em decorrência da expansão e da concentração de edificações. Esse processo tem resultado em mudanças nas propriedades, tais como permeabilidade e porosidade, e no comportamento dos solos, em face da ocorrência de chuvas, com efeitos notórios, principalmente na dinâmica hidrológica das bacias hidrográficas (Tucci, 2008; Thielen et al., 2012; Hammond et al., 2013). Neste contexto, merecem destaque os processos de compactação e impermeabilização que implicam acentuada redução da capacidade de infiltração dos solos, resultando no aumento da razão entre o volume escoado e o total precipitado. Em se tratando de eventos pluviométricos excepcionais, como aqueles de intensidade maior que $50 \mathrm{~mm} / \mathrm{h}$, podem ocorrer situações críticas, nas quais o aumento da velocidade proporciona a convergência de grandes volumes de escoamento, resultando em picos de vazão (Porto, 1995; Garotti; Barbassa, 2010; O’Driscoll et al., 2010).

Na Região Metropolitana de Goiânia, a crescente valorização de terrenos já densamente ocupados e localizados em regiões centrais ou próximos de grandes vias de circulação tem influenciado na superutilização de áreas aptas à construção de moradias. Com isso, os 
lotes passaram a ser cada vez menores e com maior área efetivamente construída, resultando em áreas densamente edificadas (Morell; Brandão; Sabino, 2012; IPEA, 2015; Correia et al., 2016; Kneib, 2016). Influenciou também na procura por mais áreas destinadas à habitação, resultando no avanço da construção de moradias inclusive em áreas que, pela legislação vigente, deveriam ser de preservação permanente. Neste contexto, Aparecida de Goiânia é representativa desse processo, uma vez que, no estado de Goiás, foi o município que experimentou as maiores taxas de urbanização nas últimas décadas (IBGE, 2011; Souza; Borges, 2015).

Neste sentido, o objetivo geral do presente trabalho é avaliar a intensificação do processo de expansão e adensamento urbano e sua influência na dinâmica hidrológica na bacia hidrográfica do córrego Tamanduá nos anos de 1992, 2005 e 2016. Como objetivos específicos, o trabalho propõe: a) avaliar as mudanças na cobertura e no uso, em especial, o processo de compactação e impermeabilização do solo e sua relação com o aumento dos coeficientes de escoamento superficial; b) avaliar a influência do aumento das áreas com elevados coeficientes de escoamento na velocidade e consequente redução do tempo de concentração do escoamento superficial, e c) avaliar os efeitos cumulativos desses fatores no aumento das estimativas de vazão.

Materiais e método

Localização e caracterização da área de estudos

A área de estudos compreende a bacia hidrográfica do córrego Tamanduá, afluente na margem direita do rio Meia Ponte, no município de Aparecida de Goiânia, o segundo com maior densidade demográfica da Região Metropolitana de Goiânia (Aragão; Arrais, 2013). Compreende uma área representativa do crescente processo de urbanização verificado nas últimas três décadas, e que se estendeu para além da área já densamente urbanizada e conurbada com a porção sul da capital do estado (Arrais; Pinto, 2008). Outro aspecto é que, além dos amplos interflúvios de relevo plano, agora o processo de adensamento urbano ocorre em quase todas as partes da bacia hidrográfica, como aquelas de maior declividade e próximas aos canais de drenagem, conforme pode ser verificado na Figura 1, e que têm influenciado na dinâmica hidrológica em todo o sistema. 


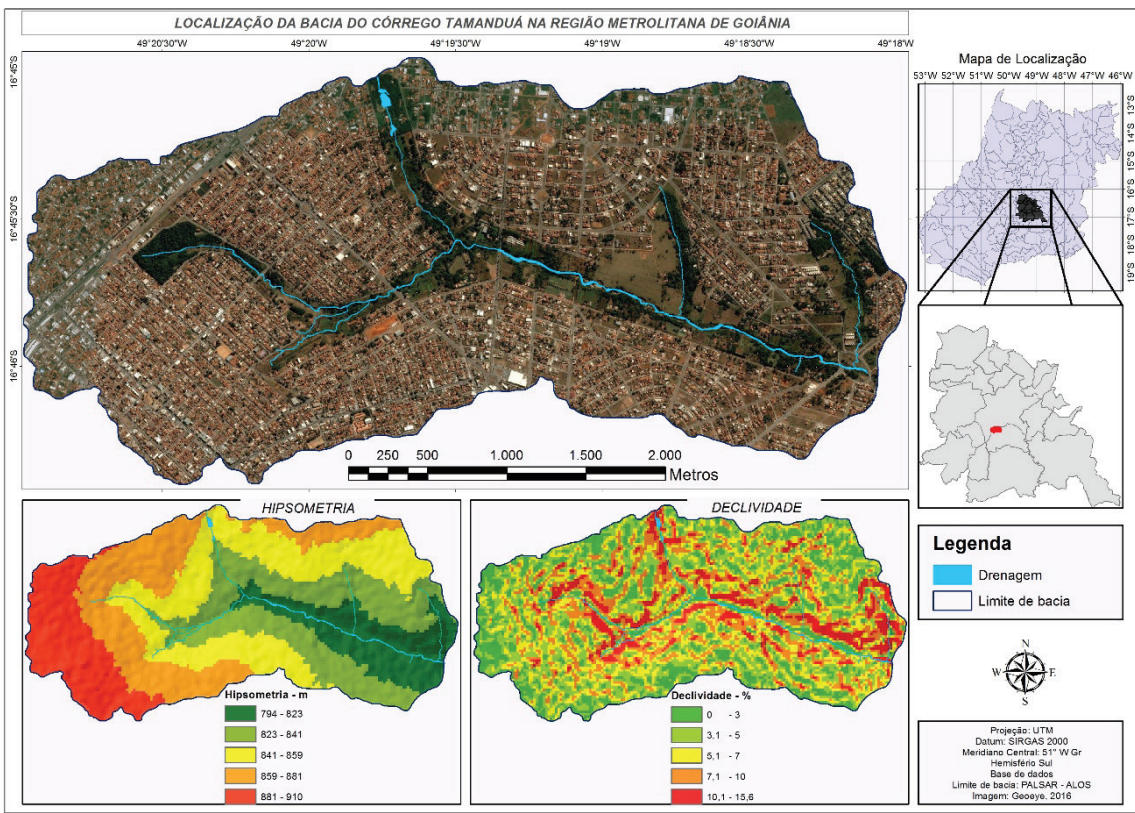

Figura 1 - Localização da bacia do córrego Tamanduá na Região Metropolitana de Goiânia.

Fonte: Elaborado pelos autores (2018)

\section{Metodologia adotada}

A metodologia consistiu na correlação espaço-temporal entre as mudanças na cobertura e no uso do solo, bem como sua correspondência em coeficientes de escoamento superficial, e o aumento das estimativas de vazão nos anos de 1992, 2005 e 2016. Para a determinação das estimativas de vazão, aplicou-se o modelo hidrológico Método Racional (Mulvaney, 1851; Kuichling, 1889), expresso pela seguinte equação:

$$
\mathrm{Qmax}=\mathrm{CiA} / 3,6
$$

(Equação 1)

Em que: Qmax = vazão máxima estimada do escoamento superficial, em m³/s; C = coeficiente de escoamento superficial ou razão entre o volume escoado e o total precipitado, adimensional; $\mathrm{i}=$ média das intensidades máximas de precipitação, em $\mathrm{mm} / \mathrm{h}$, com duração do evento 
pluviométrico igual ou maior que o tempo de concentração do escoamento superficial, e A = área da bacia, em $\mathrm{km}^{2}$.

Para tanto, os coeficientes de escoamento superficial foram determinados com base na proposta do Soil Conservation Service (SCS) - U. S. Department of Agriculture (1971), a qual foi revisada e aplicada pela Federal Highway Administration (FHA) - U.S. Department of Transportation (2013), e baseou-se inicialmente na precipitação efetiva, a qual resulta da relação entre a precipitação considerada e a capacidade de infiltração de água no solo, como apresentado na seguinte equação:

$$
P e=\frac{(p-0,2 s)^{2}}{(p+0,8 s)}
$$

(Equação 2)

Em que: $\mathrm{Pe}=$ precipitação efetiva convertida em escoamento superficial, em mm; $\mathrm{P}$ = precipitação máxima considerada, em mm, e $\mathrm{S}$ = coeficiente de armazenamento, em $\mathrm{mm}$. Este resulta da relação entre grupos hidrológicos, os quais decorrem da avaliação das características dos solos, especialmente textura e profundidade, e o tipo de cobertura e uso, resultando em valores de CN (número de escoamento), conforme o Natural Resources Conservation Service (NRCS) - USDA (1997), por meio da seguinte equação:

$$
S=\frac{25400}{C N}-254
$$

(Equação 3)

Como observado na Equação 2, essa relação considera também uma perda inicial de cerca de $20 \%$ do volume precipitado em decorrência das interceptações e retenções em depressões. Já os coeficientes de escoamento resultaram da razão entre o volume de escoamento superficial e a precipitação total considerada, como apresentado na seguinte equação:

$$
C=\left[\frac{(p-0,2 S)^{2}}{(P+0,8 S)}\right] * 1 / P
$$

(Equação 4)

Em que: $\mathrm{C}=$ coeficiente de escoamento superficial ou razão entre o volume escoado e o total precipitado, adimensional. 
Os mapas de cobertura e uso do solo foram elaborados por meio da avaliação sequencial e lógica a partir de fotografias aéreas de 1992 em níveis de cinza (IPLAN, 1992) e imagens dos satélites Quickbird de 2005 e Geoeyede de 2016, coloridas, todas com resolução espacial de $50 \mathrm{~cm}$, por meio de classificação supervisionada, classificador máxima verossimilhança e validações de campo para as áreas que se mantiveram inalteradas. Já para a elaboração dos modelos de declividade e comprimento de fluxo, utilizou-se do Modelo Digital de Elevação ALOSPALSAR, corrigido e com resolução espacial de 12,5 metros. Os resultados, especialmente da aplicação das Equações 2, 3 e 4, utilizando-se dos valores de $\mathrm{CN}$ e considerando uma precipitação de 78,46 mm para o ano de 2016, podem ser conferidos na Tabela 1, na qual são apresentadas as principais classes de cobertura e uso do solo consideradas e mapeadas para cada ano avaliado.

\begin{tabular}{l|r|r|r|r}
\hline \multicolumn{1}{c|}{ Condição do terreno } & \multicolumn{1}{c|}{ CN } & \multicolumn{1}{c|}{ S - mm } & \multicolumn{1}{c}{ Precipit. Efetiva - mm } & \multicolumn{1}{c}{ Coef. Esc. Sup. } \\
\hline Área edificada & 98 & 5,18 & 72,56 & 0,925 \\
\hline Superfície pavimentada & 97 & 7,86 & 69,76 & 0,889 \\
\hline Solo exposto compactado & 76 & 80,21 & 27,32 & 0,348 \\
\hline Solo exposto não compactado & 68 & 119,53 & 17,10 & 0,218 \\
\hline Gramínea compactada & 66 & 130,85 & 14,93 & 0,190 \\
\hline Gramínea não compactada & 61 & 162,39 & 10,15 & 0,129 \\
\hline Árvores isoladas & 62 & 155,68 & 11,03 & 0,141 \\
\hline Mata de galeria & 29 & 621,86 & 3,66 & 0,047 \\
\hline
\end{tabular}

Tabela 1 - Classes de uso e ocupação do solo e respectivos coeficientes de escoamento superficial.

Fonte: Elaborado a partir dos dados de CN constantes em Tucci e Marques (2001), por meio das equações 2, 3 e 4.

As médias das intensidades máximas de precipitação foram estimadas de acordo com a relação proposta por Vilela e Mattos (1975), que relaciona a intensidade-duração-frequência (IDF) dos eventos meteorológicos, utilizando o histórico de chuvas sistematizado por Oliveira et al. (2005) para a região de Goiânia, por meio da seguinte equação:

$$
I m=\frac{\mathbf{K} \times \operatorname{Tr}^{\mathrm{a}}}{(\mathrm{t}+\mathbf{b})^{\mathrm{c}}}=>\quad I m=\frac{920,45 \times \operatorname{Tr}^{0,1422}}{(\mathrm{t}+12)^{0,7599}}
$$




\section{(Equação 5)}

Em que: $\mathrm{Im}=$ média das intensidades máximas de precipitação, em $\mathrm{mm} / \mathrm{h} ; \mathrm{K}, a, b$ e $c=$ parâmetros próprios da estação climatológica; T $=$ tempo de retorno, em anos, para um evento extremo, e $\mathrm{t}=$ tempo de concentração do escoamento superficial que deve ser menor ou igual ao tempo de duração da precipitação na área da bacia, em minutos. No presente trabalho, considerou-se um tempo de retorno de 12 anos, compatível com áreas comerciais e artérias de tráfego (Porto et al., 2004). Já os tempos de duração das precipitações resultaram do tempo de concentração do escoamento superficial, de toda a bacia, estimados para os anos de 1992, 2005 e 2016. Estes foram determinados pelo Método Cinemático, conforme o SCS-USDA (1971), por meio da seguinte equação:

$$
T c=1 / 60 \times \Sigma \frac{L i}{V i}
$$

(Equação 6)

Em que: Tc = tempo de concentração do escoamento superficial, em min; 1/60 fator de transformação de segundos para minutos; Li: comprimento de fluxo no segmento considerado, em $\mathrm{m}$, e Vi = velocidade do escoamento superficial, em $\mathrm{m} / \mathrm{s}$.

A velocidade de escoamento superficial foi estimada com base na avaliação dos coeficientes de escoamento e da declividade, conforme proposto por Porto (1995), por meio da seguinte equação:

$$
\mathrm{Vi}=\mathrm{CV} \times \mathrm{Si}^{0,5}
$$

\section{(Equação 7)}

Em que: $\mathrm{Vi}=$ velocidade de escoamento superficial, em $\mathrm{m} / \mathrm{s} ; \mathrm{C}=$ coeficiente de escoamento superficial, adimensional, e $\mathrm{Si}=$ declividade, em \%, elevada ao expoente 0,5 .

Pelo fato de a bacia apresentar área superior a $3 \mathrm{~km}^{2}$, aplicou-se um coeficiente de retardamento em função da sua área, resultando no que se conhece como Método Racional Modificado, conforme proposto por Pinto et al. (1976) e Euclydes (1987), cuja fórmula é apresentada: 


$$
\theta=0,278-0,00034 S
$$

(Equação 8)

Em que: $\theta$ = coeficiente de retardamento em função da área da bacia; 0,278 e 0,00034 são constantes e $S=$ área da bacia $\mathrm{em}^{\mathrm{km}^{2}}$. A variável área da bacia foi utilizada de forma cumulativa, isto é, transferência do volume de células a montante para aquela a jusante, resultando no acúmulo de escoamento superficial em função da área de contribuição específica (Nunes, 2015). Esse artifício proporcionou a aplicação de todas as equações e, consequentemente, de todos os cálculos para cada uma das 65.894 células de 12,5 x 12,5 m do MDE, pertencentes à bacia, o que permitiu a elaboração de um modelo espacialmente distribuído, com o maior valor de estimativa de vazão correspondendo ao exutório da bacia. Do contrário, ter-se-ia realizado apenas um cálculo, com o valor resultante sendo representativo de toda a área da bacia, sem uma representação da variabilidade espacial dos volumes de escoamento. Todos os procedimentos técnico-operacionais desta metodologia foram desenvolvidos por meio dos módulos Math e Hydrology, disponíveis no SIG ArcGIS (ESRI) ${ }^{1}$.

\section{Resultados e discussão}

\section{Mudanças na cobertura e no uso e redução da capacidade de infiltração na bacia}

Das mudanças na cobertura e no uso e suas implicações na redução da capacidade de infiltração dos solos, destaca-se que no ano de 1992, apesar do pequeno percentual de área edificada, as classes de solo exposto não compactado, solo exposto compactado e principamente gramínea não compactada, somadas, já ocupavam cerca de 65\% da área da bacia, conforme apresentado na Figura 2. 


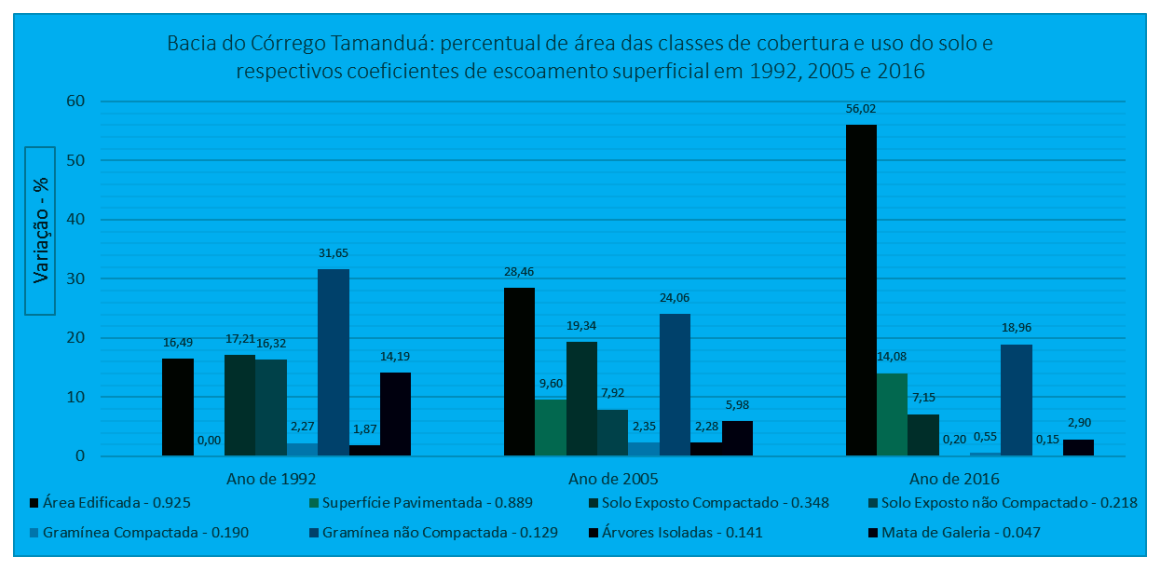

Figura 2 - Variação e área relativa - \% - das classes de cobertura e uso do solo e respectivos coeficientes de escoamento superficial entre nos anos de 1992, 2005 e 2016.

Fonte: Elaborado pelos autores (2018).

Para o referido ano, dois aspectos merecem destaque. Um diz respeito ao elevado percentual de áreas, tais como gramíneas e solo exposto, que, nos anos seguintes, foram gradativamente convertidas em área edificada e ruas pavimentadas, respectivamente. Outro refere-se ao solo exposto compactado que, em terreno com até $11 \%$ de declive e coeficiente de escoamento de 0,348 , já limitava a capacidade de retenção de água e, consequentemente, alterava o regime hidrológico, aumentando a velocidade de escoamento superficial ao longo das ruas.

As mudanças na cobertura e no uso ficaram mais evidentes no ano de 2005, quando o processo de compactação e impermeabilização do solo se mostrou mais acentuado, devido ao aparecimento da superfície pavimentada que, somada à área edificada e ao solo exposto compactado, passou a corresponder a cerca de $57 \%$ de toda a bacia. Nessa situação, merece destaque a classe de área edificada que, além de corresponder a $28 \%$ do total, apresenta elevado coeficiente de escoamento superficial, cujo volume resultante recai sobre a superfície pavimentada e, em seguida, no solo exposto compactado de ruas ainda não pavimentadas. Essas áreas, com elevados coeficientes de escoamento superficial e localizadas nas porções mais elevadas, passaram a exercer cada vez mais pressão sobre os poucos remanescentes de vegetação que, naquele ano, somavam menos de $6 \%$ da área total e localizavam-se nas porções mais rebaixadas da bacia. 
Já no ano de 2016, a bacia como um todo já apresentava sinais de consolidação do processo de edificação. Considerando toda a área, cerca de $56 \%$ encontrava-se edificada e cerca de $14 \%$, pavimentada. Se somada à área de solo exposto compactado no referido ano, cerca de $77 \%$ da bacia encontrava-se com coeficientes de escoamento superficial variando de 0,348 a 0,925 . As áreas ainda consideradas com algum potencial de infiltração, como a mata de galeria, ocorriam em menos de $3 \%$ da bacia. Os demais 19\% referentes à classe de gramínea não compactada correspondiam aos poucos terrenos ainda não edificados e localizados nas proximidades dos canais de drenagem. Parte desse estado de degradação foi apontado por Santana (2011), quando destacou que, das nove nascentes, apenas duas encontravam-se em estado de preservação, e por Carneiro e Barreira (2015), que ressaltaram o aumento da pressão antrópica na forma da remoção da vegetação, ocupação de Áreas de Preservação Pemanente, compactação dos solos e ocorrência de inundações. Em trabalho recente, Moreira Junior et al. (2016) destacaram ausência de cobertura vegetal e elevado estágio de degradação das margens, com a ocorrência de grandes erosões de borda, chegando a comprometer ruas e residências. Processos e tendências semelhantes foram constatados por Matos et al. (2011), quando analisaram as mudanças na cobertura e no uso na bacia do igarapé Tucunduba em Belém - PA. Na ocasião, ficou constatado que os solos com elevado potencial de infiltração foram os que mais tiveram redução relativa na capacidade de infiltração, em decorrência do avanço da urbanização e do adensamento urbano.

Compactação e impermeabilização do solo e alterações na dinâmica hidrológica

Tendo como referência o modelo hidrológico aplicado, com foco principalmente na relação intensidade e duração dos eventos de precipitação em face das condições do terreno, é possível perceber os efeitos da redução em larga escala da capacidade de infiltração dos solos nas estimativas de aumento do volume de escoamento superficial. Para tanto, as coleções de mapas elaboradas representam, de forma sistematizada, as condições de cobertura e uso do solo e sua correspondência em coeficientes de escoamento superficial, que, em face da intensidade e da duração do evento pluviométrico, resultam em estimativas de vazão. 
Considerando o exposto, para o ano de 1992, a área edificada predominava nas porções mais elevadas da bacia, especialmente ao longo das grandes vias, como rodovias estaduais e avenidas principais circundadas por áreas de solo exposto. Com isso, tem-se uma gradação de coeficientes de escoamento superficial variando de 0,925 , em terrenos edificados e declividades de até $11 \%$, a 0,218 em áreas pouco edificadas e ruas em condições de solo exposto (partes $a$ e $b$ da Figura 3). Nessas condições, a velocidade de escoamento superficial variou de 1,51, em superfícies de elevado coeficiente e baixa declividade, a $3,52 \mathrm{~m} / \mathrm{s}$ em superfícies com coeficientes igualmente elevados e mais inclinadas. Nas baixas vertentes, os fluxos de velocidades mais elevadas eram interceptados por áreas com gramíneas de coeficientes mais baixos, o que permitia redução das velocidades para menos de $0,5 \mathrm{~m} / \mathrm{s}$ já nas proximidades dos canais principais (parte $c$ ). Nessas condições de coeficientes e de velocidade de escoamento, e considerando uma intensidade de precipitação de $73,89 \mathrm{~mm} / \mathrm{h}$ por um período de $31 \mathrm{~min}$ (parte $e$ ), obteve-se uma estimativa de vazão máxima de $16,2 \mathrm{~m}^{3} / \mathrm{s}$ no ponto de máxima convergência considerado, conforme demonstrado na parte $f$ da mesma figura. Com base na mesma figura, é possível perceber que os mapas de comprimento de fluxo e de tempo de concentração do escoamento superficial são muito semelhantes em termos de distribuição espacial. Tal semelhança se deve à divisão dos valores de comprimento de fluxo pelas velocidades encontradas na bacia. No entanto, devido ao aumento generalizado da velocidade de escoamento na área da bacia, para os próximos anos, a tendência será da redução do tempo de concentração do escoamento superficial, que, em termos de representação espacial, implicará o recuo a montante da maior e consequente maior abrangência espacial das menores classes de tempo de concentração. 

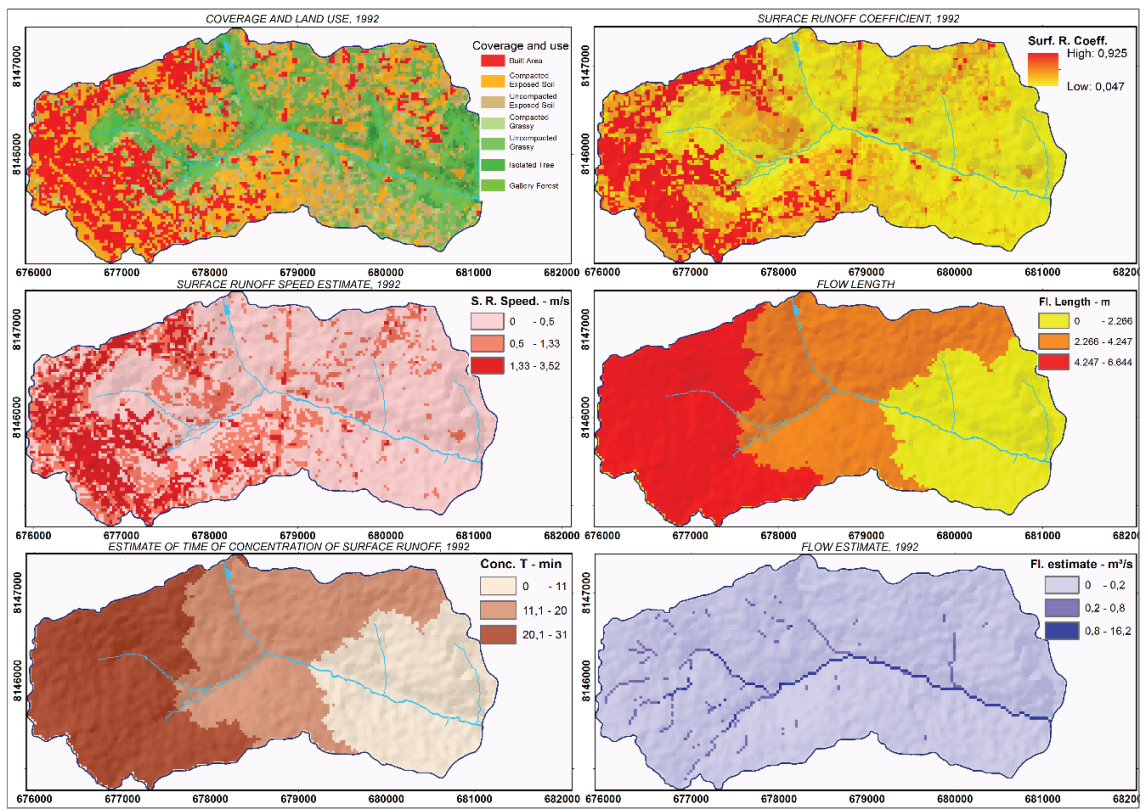

Figure 3: coverage and use maps (a); of flow coefficients (b); of flow velocity (c); of flow length (d); of concentration time (e); and of flow estimate (f) of 1992.

Fonte: Elaborado pelos autores (2018).

Para o ano de 2005, além da expansão de áreas edificadas para as médias vertentes, destaca-se o surgimento da área pavimentada correspondente a rodovias estaduais, Anel Viário, ruas e avenidas principais, além do pátio de edificações de grande porte nas imediações. A classe de solo exposto compactado apresentou um leve aumento em relação ao ano de 1992 pelo fato de, além de ocorrer em meio à área edificada, se estender também por outros ambientes, os quais anteriormente estavam ocupados por solo exposto não compactado e principalmente gramíneas, resultando em coeficientes de escoamento superiores a 0,348 em mais de $57 \%$ da bacia, conforme ilustrado nas partes $a$ e $b$ da Figura 4 . As velocidades de escoamento superficial acima de 1,33 m/s, que em $1992 \mathrm{se}$ restringiam às porções mais elevadas, em 2005 passaram a predominar também nas médias vertentes e com estimativas de até $3,57 \mathrm{~m} / \mathrm{s}$ (parte $c$ da mesma figura). Nessa situação, dois aspectos merecem ser destacados. Um refere-se à incidência de fluxos com elevada velocidade de escoamento 
superficial em áreas de solo exposto, elevando significativamente o risco de ocorrência de processos erosivos ao longo de ruas e avenidas. O outro diz respeito ao aumento de áreas com elevados coeficientes de escoamento superficial, cujos efeitos convergem para áreas de remanescentes de vegetação cada vez menores, o que implica a configuração espaço-temporal de aumento da pressão antrópica. Essa intensificação pode ser constatada a partir da observação conjunta das partes $c$ e $e$ da Figura 4, nas quais se percebe, de uma forma geral, o aumento da velocidade e a redução do tempo de concentração do escoamento superficial em relação ao ano de 1992.

Em relação ao tempo de concentração, destaca-se que, em 1992, eram necessários cerca de 31 minutos para que toda a área da bacia pudesse contribuir no ponto mais a jusante considerado, ao passo que, no ano de 2005, esse período passou a ser de 29,2 minutos. Considerando a divisão do tempo de concentração em classes, destaca-se que, no ano de 2005, houve aumento das áreas abrangidas pelas classes de 0 a 11 e de 11,1 a 20 minutos, ao passo que a área da classe maior que 20 minutos sofreu redução. Na prática, a menor abrangência da classe de 20 a 29,2 minutos significa menor tempo necessário para que toda a bacia pudesse contribuir com o escoamento no exutório. Nessas condições, e considerando os coeficientes de escoamento superficial sob uma intensidade de precipitação de 75,63 $\mathrm{mm} / \mathrm{h}$ durante um período de 29,2 minutos, a estimativa foi de uma vazão máxima de 29,6 m³/s no ponto de máxima convergência considerado, conforme demonstrado na parte $f$ da Figura 4. Em comparação com as estimativas de 1992, é possível constatar que houve redução da área com estimativa variando de 0 a $0,2 \mathrm{~m} 3 / \mathrm{s}$ e um significativo aumento da área com estimativa variando de 0,2 a $0,8 \mathrm{~m}^{3} / \mathrm{s}$. 


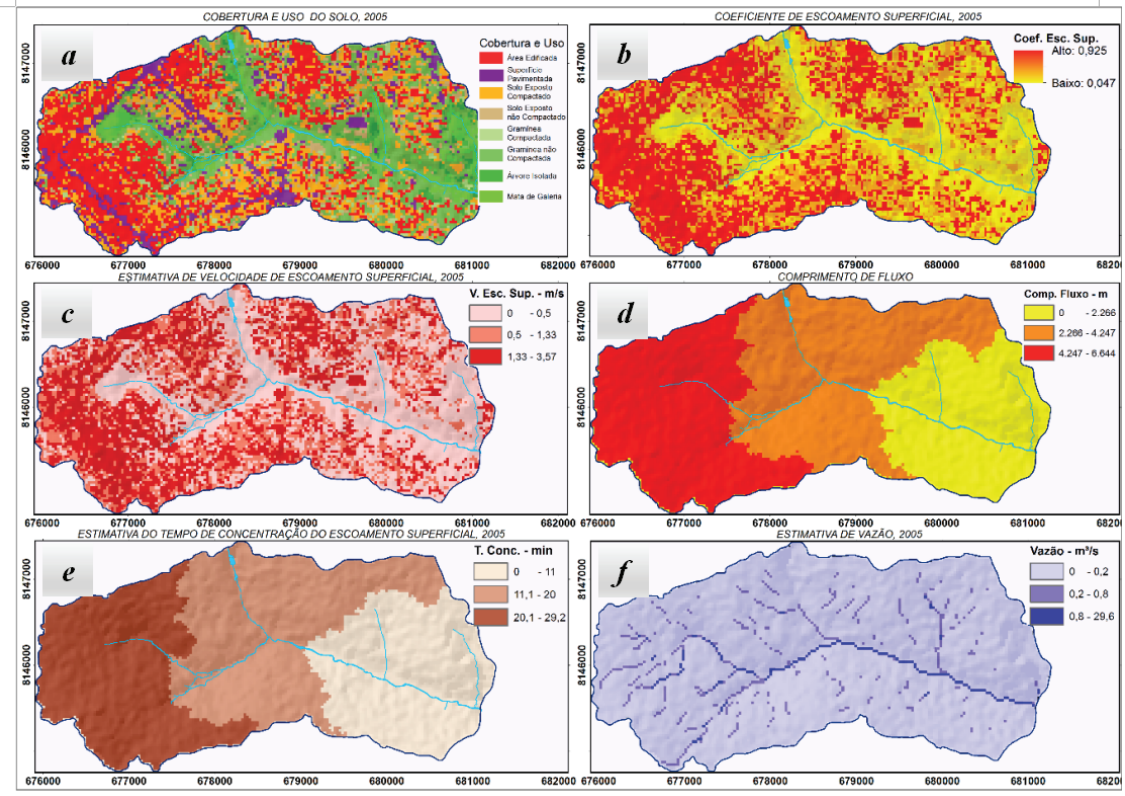

Figura 4 - Mapas de cobertura e uso (a); de coeficientes de escoamento $(b)$; de velocidade de escoamento $(c)$; de comprimento de fluxo $(d)$; de tempo de concentração (e), e de estimativa de vazão $(f)$ de 2005.

Fonte: Elaborado pelos autores (2018).

Já para o ano de 2016, houve um significativo aumento das áreas compactadas e principalmente impermeabilizadas em quase todos os setores da bacia, ao passo que as áreas de gramíneas não compactadas e mata de galeria restavam em poucos segmentos nas imediações dos canais principais. Nessa situação, as áreas de coeficientes de escoamento superficial superior a 0,89 já predominavam em cerca de $70 \%$ da área e aquelas igual a $0,348 \mathrm{em} 7 \%$, compreendendo desde os altos até os segmentos baixos e finais das vertentes. Nesse contexto, uma grande diferença em relação ao ano de 2005 está na área edificada, que dobrou em termos de abrangência, passando a ocupar cerca de 56\% da bacia. Destaca-se também o quase desaparecimento da classe de solo exposto não compactado, que, de $7 \%$ em 2005, passou para $0,2 \%$ em 2016, conforme ilustrado na parte $a$ da Figura 5. Tal redução se deve ao avanço e ao adensamento da urbanização que em 2005 predominava nas partes mais elevadas e intermediárias de 
forma rarefeita, ao passo que em 2016 passou a ocupar de forma homogênea quase toda a área da bacia, deixando cerca de 70\% dela com coeficientes de escoamento superficial acima de 0,89 (parte $b$ da mesma figura). $\mathrm{O}$ efeito dessas mudanças na velocidade de fluxo pode ser constatado na parte $c$ da Figura 5, na qual é possível perceber em quase toda a bacia, especialmente nas porções mais elevadas e médias, o predomínio de velocidades acima de $1,33 \mathrm{~m} / \mathrm{s}$, podendo alcançar até $3,82 \mathrm{~m} / \mathrm{s}$, em segmentos de elevados coeficientes associados a declives de até $11 \%$.

O predomínio de elevadas velocidades de escoamento desde as porções mais elevadas até os segmentos intermediários sugere que a redução do tempo de concentração do escoamento superficial nos segmentos mais elevados das vertentes tenha sido bem maior que a redução constatada na bacia como um todo, ao longo do período considerado. Isso porque, em termos de comprimento de fluxo, os canais são até nove vezes maiores do que as vertentes e as mudanças na cobertura e no uso ao longo da planície fluvial foram menos intensas do que aquelas constatadas nas partes mais elevadas das vertentes nos últimos 24 anos. Com isso, embora seja constatado aumento da área das classes de 0 a 11, de 11,1 a 20 e consequente redução da classe de 20,1 a 25,7 minutos do tempo de concentração, entende-se que, considerando a bacia como um todo, o canal de drenagem com a sua sinuosidade, juntamente com as menores mudanças na cobertura e no uso ao longo da planície, contribuiu para a redução de apenas 5,3 minutos no tempo de concentração do escoamento superficial no período analisado.

Nas condições do ano de 2006, com o predomínio de elevados coeficientes de escoamento superficial na maior parte da bacia e considerando uma intensidade de precipitação de 78,43 $\mathrm{mm} / \mathrm{h}$ durante um período de 25,7 minutos, a estimativa foi de uma vazão máxima de $46,8 \mathrm{~m}^{3} / \mathrm{s}$ no ponto de máxima convergência considerado, conforme demonstrado na parte $f$ da Figura 5. 

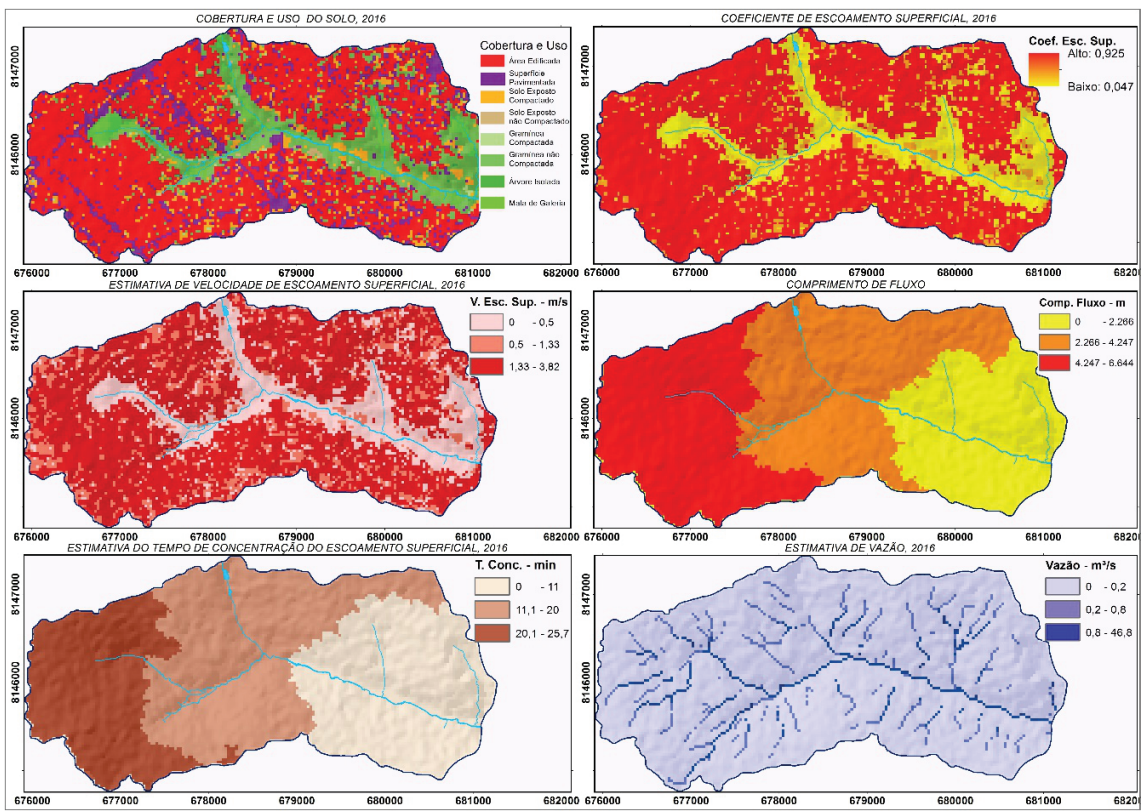

Figura 5 - Mapas de cobertura e uso (a); de coeficientes de escoamento

$(b)$; de velocidade de escoamento $(c)$; de comprimento de fluxo $(d)$; de tempo de concentração (e), e de estimativa de vazão $(f)$ de 2016.

Fonte: Elaborado pelos autores (2018).

\section{Considerações finais}

O trabalho envolvendo modelagem por meio de estimativas visa permitir que a representação de um dado processo ou fenômeno da realidade assuma um caráter mais cinemático, espacialmente contínuo e, por consequência, preencha cada vez mais as lacunas no espaçotempo, tendo em vista o caráter estático e pontual de dados mensurados diretamente em campo. No entanto, conforme ressaltado por Mitasova et al. (2006), os modelos se tornam mais precisos e eficientes na medida em que são feitos comparações ou confrontamentos entre os cenários preditos e o que de fato ocorre na realidade. Do exposto, pode-se afirmar que nenhuma das formas de obtenção de dados se sobrepõe, mas que ambas se 
complementam. Isso porque a representação de processos e fenômenos com elevada variabilidade espaço-temporal, como o escoamento superficial, a partir de dados levantados diretamente em campo se mostra extremamente difícil, tendo em vista a necessidade de uma elevada quantidade de dados, bem como os custos envolvidos em monitoramentos dessa natureza. Os modelos nascem dessa dificuldade e principalmente da necessidade de se prever cenários para os quais não existem dados, mesmo em pequena quantidade, permitindo assim fazer previsões. É por isso que os modelos resultam da análise sistematizada de dados e variáveis, bem como das tendências observadas, o que lhes confere uma forma valiosa para se avaliar os efeitos decorrentes da convergência de fatores que permitem diagnósticos e prognósticos mais precisos. No que se refere ao uso do método CN em estimativas de escoamento superficial, Soares et al. (2017) destacam boas correlações alcançadas com base na comparação entre os valores preditos e a realidade observada em diversas bacias hidrográficas.

Em relação à metodologia e aos resultados ora apresentados neste trabalho, dois aspectos merecem ser destacados. Um refere-se ao fato de que, diante da heterogeneidade dos tipos de uso e cobertura, bem como de solos, não se recorreu ao artifício de médias, mesmo que ponderadas, para se estabelecer os coeficientes de escoamento superficial da área da bacia. Todas as células de 0,5 x 0,5 m de cada imagem foram devidamente avaliadas e classificadas quanto aos mais prováveis efeitos proporcionados ao terreno quando da ocorrência de chuvas. Outro refere-se ao efeito proporcionado pela transferência do volume excedente de células a montante para aquelas a jusante, de forma cumulativa, o que resultou em um encadeamento sequencial e lógico de linhas, bem como volumes de fluxos estimados, conforme ocorre de fato no terreno. Esse artifício se mostra de grande importância, uma vez que permite avaliar qualiquantitativamente a relação causa-efeito de um fenômeno em relação ao seu entorno e a variáveis condicionantes.

Em relação à redução do tempo de concentração do escoamento superficial, ressalta-se que, embora no período considerado tenha havido uma diminuição de apenas 5,3 minutos, é importante destacar que essa redução pode ter sido maior nas porções mais elevadas das vertentes, especialmente nos segmentos de maior declividade e que passaram por mudanças significantes na cobertura e no uso nos últimos 24 anos. Com isso, destaca-se a necessidade de uma abordagem complementar e 
envolvendo apenas as áreas de vertente. A principal diferença incidirá no cálculo da velocidade de escoamento superficial, não envolvendo os canais de drenagem, uma vez que a planície e, principalmente, o canal fluvial são áreas que menos passaram por mudanças na cobertura e no uso. Tal estratégia permitirá a avaliação de mudanças do comportamento do fluxo hídrico em superfície e quando do contato com os canais de drenagem.

Outra sugestão, e que permitirá uma compreensão mais abrangente acerca dos efeitos do adensamento na dinâmica hidrológica de bacias urbanas, refere-se à avaliação da influência da pressão antrópica resultante no equilíbrio dos canais de drenagem, bem como ao longo de toda a planície fluvial. Isso porque, em termos hidrológicos, toda a pressão exercida na forma de aumento de velocidade, bem como volume de fluxos, tende a convergir na forma de aumento e concentração de energia cinética para segmentos específicos. Tal concentração de energia necessariamente resultará na realização de trabalho, o qual se processará na forma de erosões de borda e consequente degradação da planície fluvial. Trata-se de uma maneira de essas áreas receptoras de fluxo se adaptarem às novas condições hidrológicas.

A expansão urbana e o adensamento de edificações ao longo da superfície de um sistema aberto, como a bacia hidrográfica, necessariamente implicam o aumento de fluxos hídricos superficiais, que gradativamente convergem na forma de lineamentos e se intensificam, resultando no aumento do volume de escoamento. Isso porque, tendo como referência os coeficientes de escoamento de áreas edificadas 0,925 - e de áreas com vegetação - 0,047 -, percebe-se que o processo de compactação e impermeabilização pode reduzir em até $88 \%$ a capacidade de armazenamento de água no solo. Em situações dinâmicas, como a do escoamento superficial, essa baixa capacidade de retenção gera efeitos cumulativos na medida em que cada parcela do terreno deixa de absorver um volume específico do total precipitado e o transfere para segmentos a jusante, de forma a tornar os fluxos tão intensos quanto maiores forem a velocidade e o volume de escoamento.

Nota

1 Licença: ESU993242249 / LABOGEF/IESA/UFG. 


\section{Referências}

ARAGÃO, A. L. S.; ARRAIS, T. A. Uso e regulação do solo em ambientes metropolitanos: impacto do IPTU nas finanças dos municípios da Região Metropolitana de Goiânia. Boletim de Geografia, Maringá, v. 31, n. 1, p. 67-78, jan./ abr. 2013.

ARRAIS, T. A.; PINTO, J. V. S. Integrar para segregar: uma análise comparativa do tecido urbano-regional de Goiânia e Brasília. In: COLOQUIO INTERNACIONAL DE GEOCRÍTICA: DIEZ AÑOS DE CAMBIOS EN EL MUNDO, EN LA GEOGRAFÍA Y EN LAS CIENCIAS SOCIALES 1999-2008, 10, 2008, Barcelona. Anais... Barcelona: Universidad de Barcelona, 2008.

CARNEIRO, V. A.; BARREIRA, C. C. M. A. Um estudo de caso sobre o parque do córrego Tamanduá no setor Residencial Park Garavelo em Aparecida de Goiânia (GO): parque linear urbano ou parque ecológico municipal? In: SEMINÁRIO INTERNACIONAL DE ARQUITETURA, TECNOLOGIA E PROJETO, 2015, Anápolis. Anais... Anápolis: UEG, 2015.

CORREIA, L. A. et al. Mapa de ruídos como instrumento de planejamento urbano estratégico: estudo de caso no setor Bueno, Goiânia, GO. In. CONGRESSO LUSO BRASILEIRO PARA O PLANEJAMENTO URBANO, REGIONAL, INTEGRADO E SUSTENTÁVEL, 7, 2016, Maceió. Anais... Maceió: UFAl, 2016.

EUCLYDES, H.P. Saneamento agrícola. Atenuação de cheias: metodologia e projeto. Belo Horizonte: Rural MinaS, 1987. 320 p.

FHA. Federal Highway Administration. Urban Drainage Design Manual, Hydraulic Engineering. 3. ed.. Washington D. C.: National Highway Institute, USDT, 2013. p. 478.

GAROTTI, L. M.; BARBASSA, A. P. Estimativa de área impermeabilizada diretamente conectada e sua utilização como coeficiente de escoamento superficial. Engenharia Sanitária e Ambiental, v. 15, n. 1, p. 19- 28, jan./abr. 2010.

HAMMOND, M. J.; CHEN, A. S.; DJORDJEVIĆ, S.; BUTLER, D.; MARK, O. Urban flood impact assessment: a state-of-the-art review. Urban Water Journal, v. 12. p. 14-29, 2013.

IBGE. Instituto Brasileiro de Geografia e Estatística. Sinopse do Censo Demográfico 2010. Rio de Janeiro, 2011. Disponível em <http://www.ibge.gov. br/home/presidencia/noticias/imprensa/ppts/0000000402.pdf>. Acesso em: 10 jul. 2017.

IPEA. Instituto de Pesquisa Econômica Aplicada. Caracterização e quadros de análise comparativa da governança metropolitana no Brasil: análise comparativa das funções públicas de interesse comum (componente 2). Região Metropolitana de Goiânia. Relatório de Pesquisa. Rio de Janeiro: Ipea, 2015.

IPLAN. Instituto de Planejamento Municipal. Plano de Desenvolvimento Integrado de Goiânia. Goiânia: IPLAN, 1992. 112 p. (v. 1). 
KNEIB, E. C. Centralidades urbanas e sistemas de transporte público em Goiânia, Goiás. Revista Brasileira de Gestão Urbana, v. 8, n. 3, p. 306-317, set./dez. 2016.

KUICHLING, E. The relation between the rainfall and the discharge of sewers in populous districts. Transactions of the American Society of Civil Engineers, v. 20, n. 1, p. 1-60. 1889.

MATOS, F. C.; TARGA, M. S.; BATISTA, G. T.; DIAS, N. W. Análise temporal da expansão urbana no entorno do Igarapé Tucunduba, Belém, PA, Brasil. Revista Biociências, v. 17, n. 1, p. 7-16, 2011.

MITASOVA, $H$. et al. Real-time human interaction with landscape mdels using a tangible geospatial modeling environment. IEEE Computer Graphics \& Applications, Special Issue - GeoVisualization, North Carolina, v. 26, p. 55-63, 2006.

MOREIRA JUNIOR, A. B. et al. Educação ambiental para conservação do córrego Tamanduá em Aparecida de Goiânia - GO. In: ENEEAMB E FÓRUM LATINO AMERICANO DE ENGENHARIA E SUSTENTABILIDADE, 14., 2016, Brasília. Anais... Brasília: 2016.

MORELL, M. G. G.; BRANDÃO, M. V. M.; SABINO, W. Os estados e as regiões metropolitanas constitutivas do Observatório das Metrópoles no Censo 2010. Rio de Janeiro: Instituto Nacional de Ciências e Tecnologia CNPq/FAPERJ/CAPES, 2012. 75 p.

MULVANEY, T. J. On the use of self-registering rain and flood gauges in making observations of the relations of rainfall and flood discharges in a given catchment. Trans. Inst. Civil Eng. Ireland, v. 4, p. 18-33, 1851.

NRCS. National Resources Conservation Service. Estimation of direct runoff from storm rainfall. In: __ National Engineering Handbook Hidrology Chapters. NRCS: Washington, D. C., 1997. 79 p.

NUNES, E. D. Modelagem de processos erosivos hídricos lineares no município de Mineiros - GO. 2015. 242 p. Tese (Doutorado em Geografia) - Instituto de Estudos Socioambientais, Universidade Federal de Goiás, Goiânia, 2015.

O’DRISCOLL, M.; CLINTON, S.; JEFFERSON, A.; MANDA, A.; McMILLAN, S. Urbanization effects on watershed hydrology and in-stream processes in the Southern United States. Water, v. 2, p. 605-648, 2010.

OLIVEIRA, L. F. C. et al. Intensidade-duração-frequência de chuvas intensas para localidades no estado de Goiás e Distrito Federal. Pesquisa Agropecuária Tropical, Goiânia, v. 35, n. 1, p. 13-18, 2005.

PINTO, N. L. S.; HOLTZ, A. C. T.; MARTINS, J. A.; GOMIDE, F. L. S. Hidrologia básica. São Paulo: Editora Edgard Blücher, 1976. 278 p.

PORTO, R. L. L. Escoamento superficial direto. In: TUCCI, C. E. M.; PORTO, R. L. L.; BARROS, M. T. de. (Org.). Drenagem urbana. Porto Alegre: ABRH, 1995. p. 107-162. (v. 5).

.; ZAHED, K.; TUCCI, C.; BIDONE, F. Drenagem urbana. In: TUCCI, C. E. M. (Org.). Hidrologia: ciência e aplicação. Porto Alegre: ABRH, 2004. p. 805-847. 
TANA, M. N. R. Identificação dos impactos ambientais da ocupação irregular na área de preservação permanente (APP) do Córrego Tamanduá em Aparecida de Goiânia. In: CONGRESSO BRASILEIRO DE GESTÃO AMBIENTAL, 2., 2011, Londrina. Anais... Londrina: UNOPAR, 2011.

SCS. Soil Conservation Service. Design hydrographs, section 4, hydrology. In: MOKUS, V. National Engineering Handbook, USDA, Washington D. C. , 1971. $127 \mathrm{p}$.

SOARES, M. R. G. J.; FIORI, C. O.; SILVEIRA, C. T.; KAVISKI, E. Eficiência do método Curve Number de retenção de águas pluviais. Mercator, Fortaleza, v. 16. n. 1, p. 1-16, 2017.

SOUZA, J. S.; BORGES, R. E. As migrações interestaduais para a Região Metropolitana de Goiânia: uma análise dos fluxos migratórios nos períodos 1986/1991, 1995/2000, e 2005/2010. Interface, Porto Nacional, n. 10, p. 197-209, 2015.

THIELEN, J. et al. State of the art of flood forecasting: from deterministic to probabilistic approaches. In: LAMOND, J.; BOOTH, C.; HAMMOND, F.; PROVERBS, D. (Ed.). Flood hazards: impacts and responses for the built environment. Flórida: CRC Press, 2012. p. 9-25.

TUCCI, C. E. M.; MARQUES, D. M. L. da M. Avaliação e controle da drenagem urbana. Porto Alegre: Ed. UFRGS, 2001. 558 p.

TUCCI, C. E. M. Águas urbanas. Estudos avançados, São Paulo, v. 22, n. 63, p. 97-112, 2008.

VILLELA, S. M.; MATTOS, A. Hidrologia aplicada. São Paulo: Mc Graw-Hill do Brasil, 1975. 245 p.

Elizon Dias Nunes - Licenciado, Bacharel, Mestre e Doutor em Geografia pela Universidade Federal de Goiás. Atualmente é geógrafo no Laboratório de Geomorfologia, Pedologia e Geografia Física no Instituto de Estudos Socioambientais da Universidade Federal de Goiás, onde trabalha com tratamento de dados espaciais georreferenciados e geração da informação geográfica aplicada a modelagem de fenômenos multifatoriais. ORCID: https://orcid.org/0000-0001-5430-4841

Lana Lima Borba - Bacharela em Engenharia Ambiental pela Pontifícia Universidade Católica de Goiás. Desenvolve atividades de pesquisa e consultoria em projetos nas áreas de Controle e Monitoramento Ambiental. ORCID: https://orcid.org/0000-0002-0950-3232 
Contribuições dos autores

Todos os autores prestaram substanciais contribuições científicas e intelectuais ao desenvolvimento do estudo. Os autores trabalharam em conjunto na concepção, na estruturação e na redação, bem como na revisão crítica. O autor Elizon Dias Nunes foi responsável pelo levantamento e pela estruturação do banco de dados geográficos, implementação das equações por meio de geoprocessamento e revisão textual. Para a autora Lana Lima Borba coube a tarefa de levantamento, avaliação e sistematização dos valores de coeficientes de escoamento superficial, avaliação e revisão das equações.

Recebido para publicação em 02 de abril de 2018 Aceito para publicação em 29 de maio de 2018 